\title{
Unconfined compressive strength characteristics of stabilized peat
}

\author{
Wong Leong Sing ${ }^{1,2 \star}$, Roslan Hashim ${ }^{2}$ and Faisal Ali $^{2}$ \\ ${ }^{1}$ Department of Civil Engineering, College of Engineering, Universiti Tenaga Nasional, Km 7, Jalan Kajang-Puchong, \\ 43009 Kajang, Selangor, Malaysia \\ ${ }^{2}$ Department of Civil Engineering, Faculty of Engineering, University of Malaya, Lembah Pantai, 50603 Kuala Lumpur, \\ Malaysia.
}

Accepted 29 March, 2010

\begin{abstract}
Deep stabilized peat columns could be considered as attractive and economical foundation for construction of highway embankments on deep peat ground. However, peat itself is very problematic and failure in the formation of the columns with adequate strength was often attributed to unsuitable type and insufficient dosage of binder added to the organic soil. Organic matter in peat was known to impede the cementing process in the soil, thus, retarding the early strength gain of stabilized peat. To evaluate the strength characteristics of stabilized peat, laboratory investigation on early strength gain of the stabilized soil was conducted to formulate a suitable and economical mix design that can be effectively used for the soil stabilization. To achieve such purpose, the study examined the effect of binder, sodium chloride as cement accelerator and silica sand as filler on the unconfined compressive strength of stabilized peat after 7 days of curing in water. Binders used to stabilize the peat were Ordinary Portland cement, ground granulated blast furnace slag, sodium bentonite, kaolinite, lime and bentonite. All the stabilized peat specimens were tested using unconfined compression apparatus. The test results revealed that the stabilized peat specimen (80\% OPC: $10 \%$ GGBS: $10 \%$ SB) with addition of $4 \%$ sodium chloride by weight of binder and $50 \%$ well graded silica sand by volume of wet peat at 300 $\mathrm{kg} \mathrm{m}^{-3}$ binder dosage yielded the highest unconfined compressive strength of $196 \mathrm{kPa}$. This implied that, the higher the dosage of silica sand in stabilized peat, the more solid particles will be available for the binder to unite and form a load sustainable stabilized peat. It could be summarized that, as the rate of hydration process of stabilized peat was accelerated by inclusion of sodium chloride, the solid particles contributed to the hardening of stabilized peat by providing the cementation bonds to form between contact points of the particles.
\end{abstract}

Key words: Organic matter, binder, sodium chloride, silica sand, unconfined compressive strength.

\section{INTRODUCTION}

Peat originates from plant and denotes the various stages in the humification process where the plant structure can be discerned (Hartlen and Wolski, 1996). The decaying process of plant under acidic condition without microbial process results in the formation of organic matter in peat. This makes peat extremely soft and problematic to the type of soil. Hence, construction of highway embankments on deep peat ground without proper ground improvement may result in excessive total

\footnotetext{
*Corresponding author. E-mail: wongls79@gmail.com.
}

and differential settlements. An economical ground improvement method for deep peat ground is deep mixing technique. Deep mixing technology consists of mixing in-place soft soils with reagent (including cement or lime or a combination in a form of powder or slurry) using axis augers and mixing paddles to construct soilcement or lime columns (Xing et al., 2009). However, the effectiveness of such ground improvement method is largely dependent on the reactivity of the binder used to stabilize a soil.

It is generally recognized that organic matter tends to retard the hydration and secondary pozzolanic reactions of peat stabilized with Ordinary Portland cement (Chen 
Table 1. Basic properties of peat.

\begin{tabular}{lc}
\hline Basic soil property & Average \\
\hline Natural moisture content (\%) & 668 \\
Specific gravity & 1.40 \\
Fiber content (\%) & 90 \\
Organic content (\%) & 96 \\
Ash content (\%) & 4 \\
pH of peat & 3.51 \\
Peat soil classification & Fibrous \\
\hline
\end{tabular}

and Wang, 2006). This is possible due to the fact that black humic acid (a component of organic matter) tends to react with calcium liberated from cement hydrolysis to form insoluble calcium humic acid making it difficult for calcium crystallization, which is responsible for the increase of cement soil strength to take place (Chen and Wang, 2006). Secondary pozzolanic reaction of cement stabilized peat is retarded due to insufficient silica $\left(\mathrm{SiO}_{2}\right)$ and alumina $\left(\mathrm{Al}_{2} \mathrm{O}_{3}\right)$ that can react with calcium hydroxide $\left[\left(\mathrm{Ca}(\mathrm{OH})_{2}\right]\right.$ generated from cement hydration to form secondary calcium silicates and aluminates, which are responsible for the long term strength gain of stabilized peat (Wong et al., 2008). Furthermore, according to Axelsson et al. (2002), in soils with high organic contents, such as mud and peat, the quantity of binder needs to exceed a "threshold". At minimum, the quantity of binder added must be sufficient to build up a load-bearing skeleton (Janz and Johansson, 2002). That means stabilization of peat remains ineffective if the amount of binder added to the soil is below the threshold. Thus, more binder of a given type needs to be added to a porous, watery soil such as peat or mud than to a more densely compacted soil (Janz and Johansson, 2002).

To counteract the organic matter, sufficient cement with a small additive of sodium chloride $(\mathrm{NaCl})$ can be added to saturated peat to neutralize the black humic acid and provide adequate tricalcium silicate $\left(\mathrm{Ca}_{3} \mathrm{SiO}_{5}\right)$ that reacts with water $\left(\mathrm{H}_{2} \mathrm{O}\right)$ to produce enough calcium silicate hydrates that bind the soil particles together. In addition, inclusion of well graded silica sand increases the packing efficiency of the stabilized peat. In view of that, it is extremely important to ensure that early strength gain of stabilized peat is achieved to offset the strength retarding effect as a result of the presence of acidic organic matter in peat. Since strength of stabilized peat is often evaluated by measuring its unconfined compressive strength due to the soil low permeability and high stiffness, unconfined compression tests often provide relatively fast and cheap means of determining the soil strength. The present study focused on evaluating the early unconfined compressive strength gain of peat stabilized by different combinations and compositions of Ordinary Portland cement, sodium chloride, silica sand, kaolinite, sodium bentonite, bentonite, lime and ground granulated blast furnace slag. The study also investigated the roles of sodium chloride as cement accelerator and well graded silica sand as filler at increasing the unconfined compressive strength of stabilized peat.

\section{MATERIALS AND METHODS}

\section{Peat soil sample}

Sampling of peat for the study was carried out on a peat ground in Sri Nadi village of the district of Klang of the state of Selangor, Malaysia. For the sampling purpose, excavation of trial pits was done to a depth of $1 \mathrm{~m}$ below the ground surface in order to get both undisturbed and disturbed peat samples. Ground water table was found to be at a depth of $0.3 \mathrm{~m}$ from the ground surface. The high ground water table suggested that the peat had a very high water retention capacity. Visual inspection on the soil indicated that the soil was dark brown in colour. When the soil was squeezed and extruded between fingers, it was found to be somewhat pasty and the plant structure was hardly identifiable. Based on von Post scale on peat's degree of humification, the soil can be classified as $\mathrm{H}_{4}$. Basic properties of the peat are shown in Table 1 (Karlsson and Hansbo, 1981). From Table 1, it can be observed that while the peat was highly organic with average organic content of $96 \%$, its average fiber content of $90 \%$ implied that, the soil was fibrous in its nature. According to Landva and Pheeney (1980), the term -*-fibre includes all other fibrous structures, such as shrub rootlets, plant root hairs, rhizoids (root like filaments), etc.

\section{Stabilized soil specimen preparation}

A total of 15 stabilized peat specimens of different mix design were prepared and cured for 7 days before testing. For soil homogenization, the naturally saturated peat was allowed to pass through $2 \mathrm{~mm}$ sieve size. Materials larger than $2 \mathrm{~mm}$ sieve size like isolated roots, large fibers and stones were removed through the sieving process. A kitchen mixer was then used to initially mix the wet peat to ensure that moisture was uniformly distributed throughout the soil. Next, the soil was mixed with binder and silica sand for $10 \mathrm{~min}$ before it was filled and tamped in four layers up to $180 \mathrm{~mm}$ height in a plastic tube of $50 \mathrm{~mm}$ internal diameter and $250 \mathrm{~mm}$ height.

Each plastic tube was arranged vertically in a rack and submerged in a water tank before the specimen of each tube was allowed to be cured under a pressure of $100 \mathrm{kPa}$. While the required dosage of binder for each specimen was measured in 300 $\mathrm{kg} \mathrm{m}^{-3}$ relative to the weight of wet peat at its natural moisture content of $668 \%$ in the plastic tube, the needed amount of sodium chloride was quantified as $4 \%$ by weight of binder used for stabilizing the soil. Amount of silica sand added to a stabilized peat specimen was either 25 or $50 \%$ by volume of wet peat depending on the objective of testing. After curing, each stabilized peat specimen was extruded from the plastic tube and trimmed to a height of $100 \mathrm{~mm}$ for testing.

\section{Method of testing}

After 7 days of curing in water, unconfined compression tests were performed on all the stabilized peat specimens to determine their unconfined compressive strength. The test was also done on an undisturbed peat specimen so that the unconfined compressive strength of the soil can be compared to those of stabilized ones. All the tests were done in accordance to ASTM D 2166-06 standard. The various compositions of binder and silica sand are shown in Table 2. Soil specimen 1 in Table 2 is undisturbed peat specimen. 
Table 2. Untreated peat specimen and the various compositions of binder and silica sand of stabilized peat specimens at a binder dosage of $300 \mathrm{~kg} \mathrm{~m}^{-3}$ in unconfined compression tests.

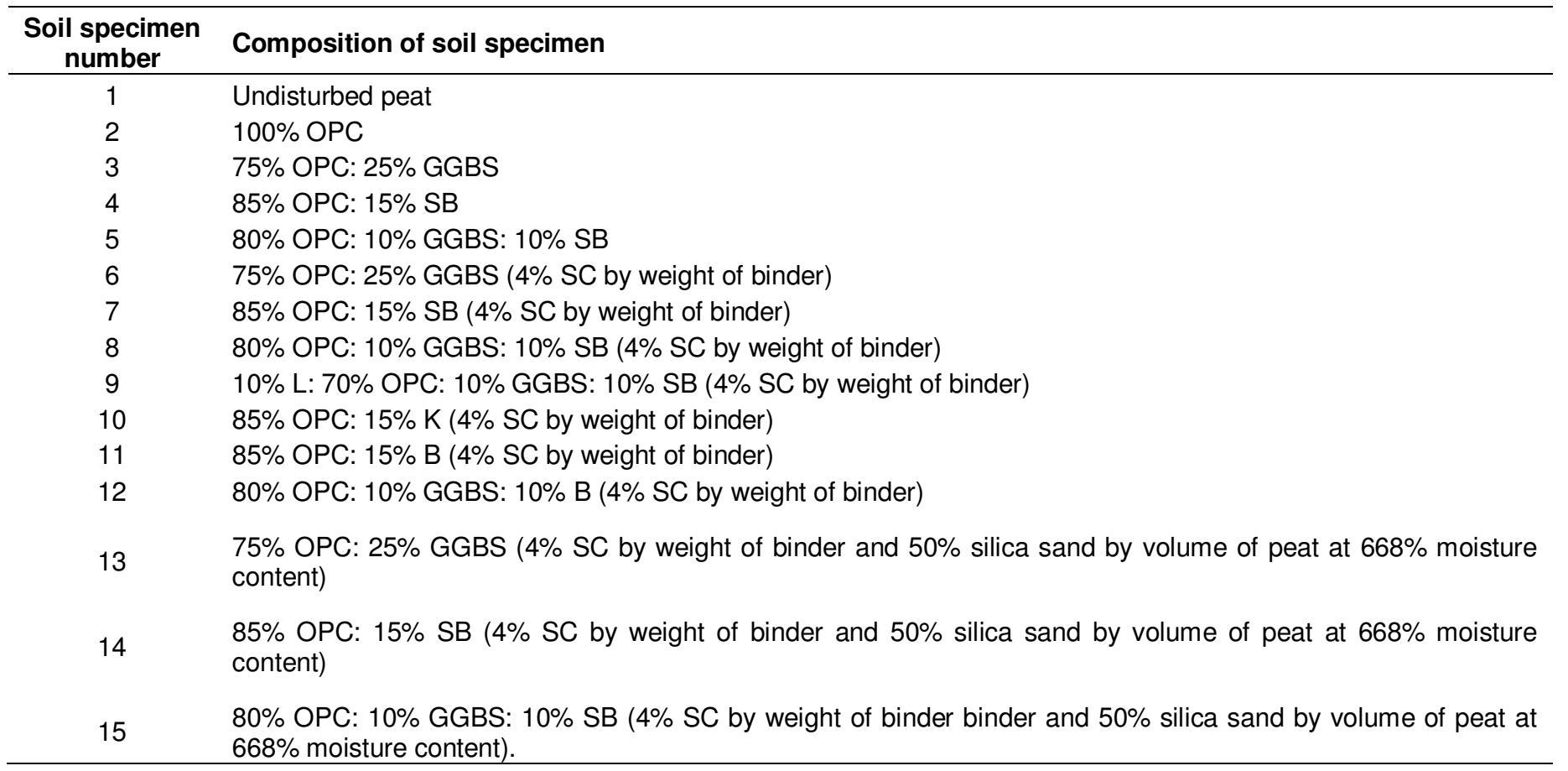

Note: OPC = Ordinary Portland Cement; GGBS = Ground Granulated Blast Furnace Slag; SB = Sodium Bentonite; L = Lime; $\mathrm{K}=\mathrm{Kaolinite} ; \mathrm{B}=$ Bentonite; SC = Sodium Chloride (Unless specified in the table, the dosage of silica sand for a stabilized peat specimen is $25 \%$ by volume of peat at $668 \%$ moisture content)

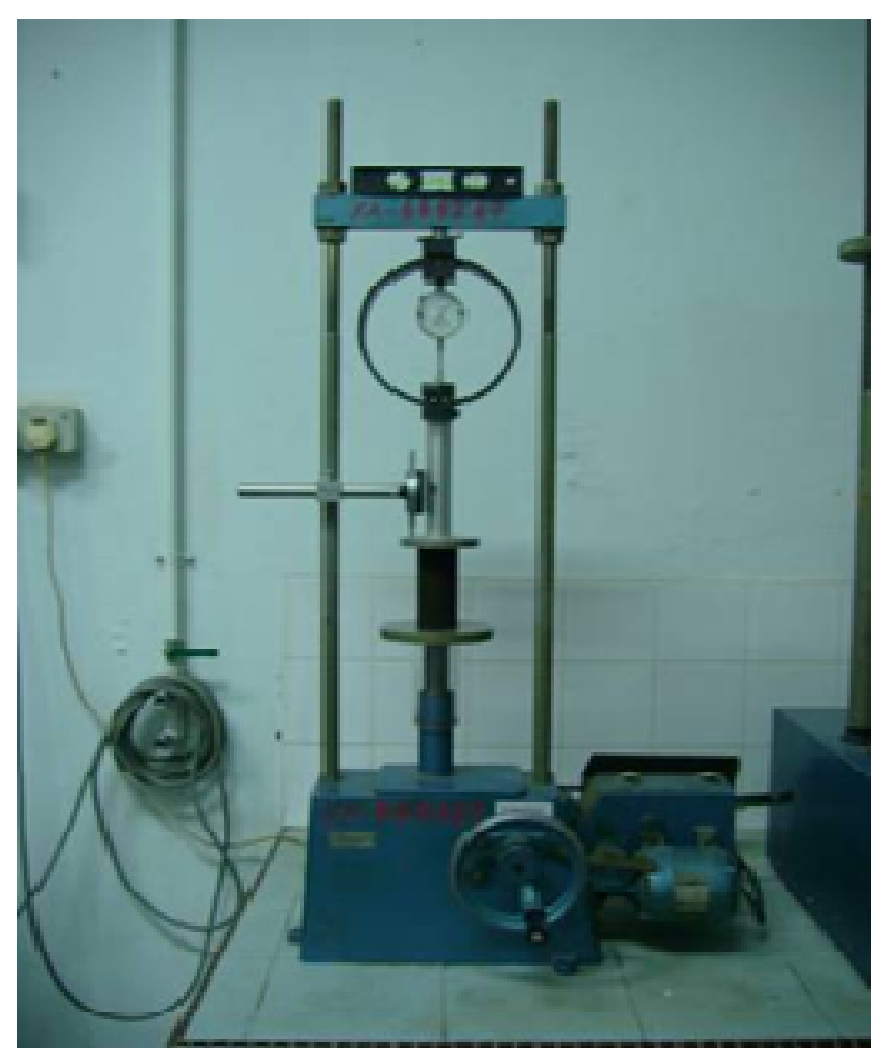

Figure 1. Unconfined compression test using $4.5 \mathrm{kN}$ load frame.
Soil specimens 2 - 5 are stabilized peat specimens with different compositions and types of binder without sodium chloride at a binder dosage of $300 \mathrm{~kg} \mathrm{~m}^{-3}$ and $25 \%$ well graded siliceous sand by volume of wet peat. Four percent sodium chloride by weight of binder was added to the next seven compositions of stabilized peat specimens (soil specimens 6 - 12) at the same dosage of binder and siliceous sand in order to observe the increase in strength of the stabilized soils as a result of sodium chloride functioning as a cement accelerator to increase the rate of cement setting time, thereby accelerating the rate of hydration reaction between cement and pore water to generate more calcium silicate hydrate crystals in the stabilized soils.

Finally, the last three specimens of stabilized peat (soil specimens 13 - 15) consist of similar dosage of binder and sodium chloride but the dosage of silica sand added to each specimen was increased to $50 \%$ by volume of wet peat in order to investigate the role of silica sand as filler at increasing the number of solid particles in it, thereby, contributing to its higher strength in comparison to that with less silica sand. Basically, inclusion of the filler produces no chemical reaction but it enhances the strength of the stabilized peat by increasing the number of soil particles available for the binders to unite and form a load sustainable stabilized soil structure (Wong et al., 2008).

\section{Principle of unconfined compression test}

In unconfined compression test, a cylindrical soil specimen of 50 $\mathrm{mm}$ diameter and $100 \mathrm{~mm}$ height is placed between the top and lower platens as shown in Figure 1. An axial load is then applied vertically in such a way the constant rate of strain of the soil specimen is $1.5 \mathrm{~mm} \mathrm{~min}^{-1}$. In other words, $1.5 \%$ vertical strain is 
applied on the specimen at every minute. This rate is so rapid relative to the drainage of the specimen that there is no time for significant volume change in spite of the absence of a membrane to seal the specimen (Terzaghi et al., 1996).

The unconfined compressive strength is taken as the peak stress of the soil stress-strain curve or if no peak stress is identified after the vertical strain reaches $20 \%$, the strength is considered as the peak stress at its $20 \%$ corresponding vertical strain. Failure of soil specimen in the test normally implies the condition in which the specimen can sustain no further increase in stress, that is, the point at which it offers its maximum resistance to deformation in term of axial stress (Head, 1994).

\section{RESULTS}

Figure 2 shows the relationship between unconfined compressive stress and vertical strain of stabilized peat specimens of different binder compositions in comparison to that of undisturbed peat specimen. At its natural state, the unconfined compressive strength of undisturbed peat was found to be $18 \mathrm{kPa}$. After stabilization of 7 curing days at a binder dosage of $300 \mathrm{~kg} \mathrm{~m}^{-3}$ and $25 \%$ silica sand by volume of wet peat, peat mixed with $75 \%$ OPC and $25 \%$ GGBS in dosage composition did not show improvement in unconfined compressive strength when the strength was found to be $17 \mathrm{kPa}$ only. At the same curing time and dosage of binder and silica sand, stabilized peat with compositions of $80 \%$ OPC: $10 \%$ GGBS: $10 \%$ SB and $85 \%$ OPC: $15 \%$ SB showed only slight improvement in unconfined compressive strength when both specimens yielded the strength of 19 and 24 $\mathrm{kPa}$, respectively.

A significant improvement in the strength could only be observed when the peat was stabilized with $100 \%$ OPC at the same curing time and dosage of binder and silica sand. The modulus of elasticity and unconfined compressive strength of the stabilized peat reached 2668 and $63 \mathrm{kPa}$, respectively. The relationship between unconfined compressive strength and vertical strain of stabilized peat specimens with each specimen added $4 \%$ sodium chloride by weight of binder is shown in Figure 3. It could be observed from Figure 3 that at $300 \mathrm{~kg} \mathrm{~m}^{-3}$ binder dosage and $25 \%$ silica sand by volume of wet peat, sodium chloride had no significant effect on the early strength gain of peat soil stabilized at binder compositions of $75 \%$ OPC: $25 \%$ GGBS, $85 \%$ OPC: $15 \%$ SB, $80 \%$ OPC: $10 \%$ GGBS: $10 \%$ SB, $85 \%$ OPC: $15 \%$ B and $80 \%$ OPC: $10 \%$ GGBS: $10 \%$ B. The specimens yielded unconfined compressive strength of 12, 27, 28, 27 and $14 \mathrm{kPa}$ respectively, which were relatively low. However, at the same dosage of binder, silica sand and sodium chloride, stabilization of peat with binder compositions of $85 \%$ OPC: $15 \% \mathrm{~K}$ and $10 \% \mathrm{~L}: 70 \%$ OPC: 10\% GGBS: $10 \%$ SB resulted in higher unconfined compressive strength when the strength of the specimens were found to be 61 and $50 \mathrm{kPa}$, respectively.

Figure 4 shows the unconfined compressive stressvertical strain relationship of stabilized peat specimens, each at a binder dosage of $300 \mathrm{~kg} \mathrm{~m}^{-3}, 50 \%$ silica sand by volume of wet peat and $4 \%$ sodium chloride by weight of binder. In general, all of the stabilized peat specimens showed markedly improvement in unconfined compressive strength when compared to that of undisturbed peat specimen. At the dosage of binder, silica sand and sodium chloride, a binder composition of $80 \%$ OPC: $10 \%$ GGBS: $10 \%$ SB yielded the highest unconfined compressive strength of $196 \mathrm{kPa}$ followed by binder compositions of $85 \%$ OPC: $15 \%$ SB and $75 \%$ OPC: $25 \%$ with the strength of 194 and $100 \mathrm{kPa}$, respectively. Modulus of elasticity in the specimens of all the three binder compositions sharply increased with the soil parameter values reached 9668, 9664 and $8064 \mathrm{kPa}$, respectively, when compared to that of undisturbed peat which was $362 \mathrm{kPa}$ only. The abrupt increase in the strength of the specimens implied that their vertical strains at failure were relatively short, which were 2.33 , 2.33 and $1.60 \%$, respectively, when compared to that of undisturbed peat, which was $8.00 \%$. This corresponded to the brittle behaviour of the specimens as the stiffer specimen was, the shorter was the corresponding vertical strain at failure and the higher the specimen unconfined compressive strength.

\section{DISCUSSION}

Influence of binder composition on the unconfined compressive strength of stabilized peat specimens without sodium chloride

While unconfined compressive strength improvement was reasonably achieved when the peat was mixed with $100 \%$ OPC in the dosage composition, no significant early strength gain could be observed in the rest of the dosage compositions of stabilized peat in Figure 2. This could be explained by the fact that when insufficient cement was added to saturated peat, provision of tricalcium silicate to neutralize the black humic acid was inadequate to induce cement hydration in the soil. Thus, the strength gain of the soil was retarded even with the presence of pozzolan like sodium bentonite (Wong, 2010). The impediment of cement hydration within the soil also implied that, inadequate calcium hydroxide were generated to react with silica and alumina in pozzolan to form secondary calcium silicate hydrate crystals, which were needed for long term strength gain of stabilized peat.

\section{Effect of sodium chloride on the unconfined compressive strength of stabilized peat specimens}

With the highest early strength gain, it was proven that kaolinite in comparison to other pozzolans in Figure 3 responded well as a pozzolanic material for Ordinary Portland cement with the help of sodium chloride to form stabilized peat soil. It was also evident from the result 


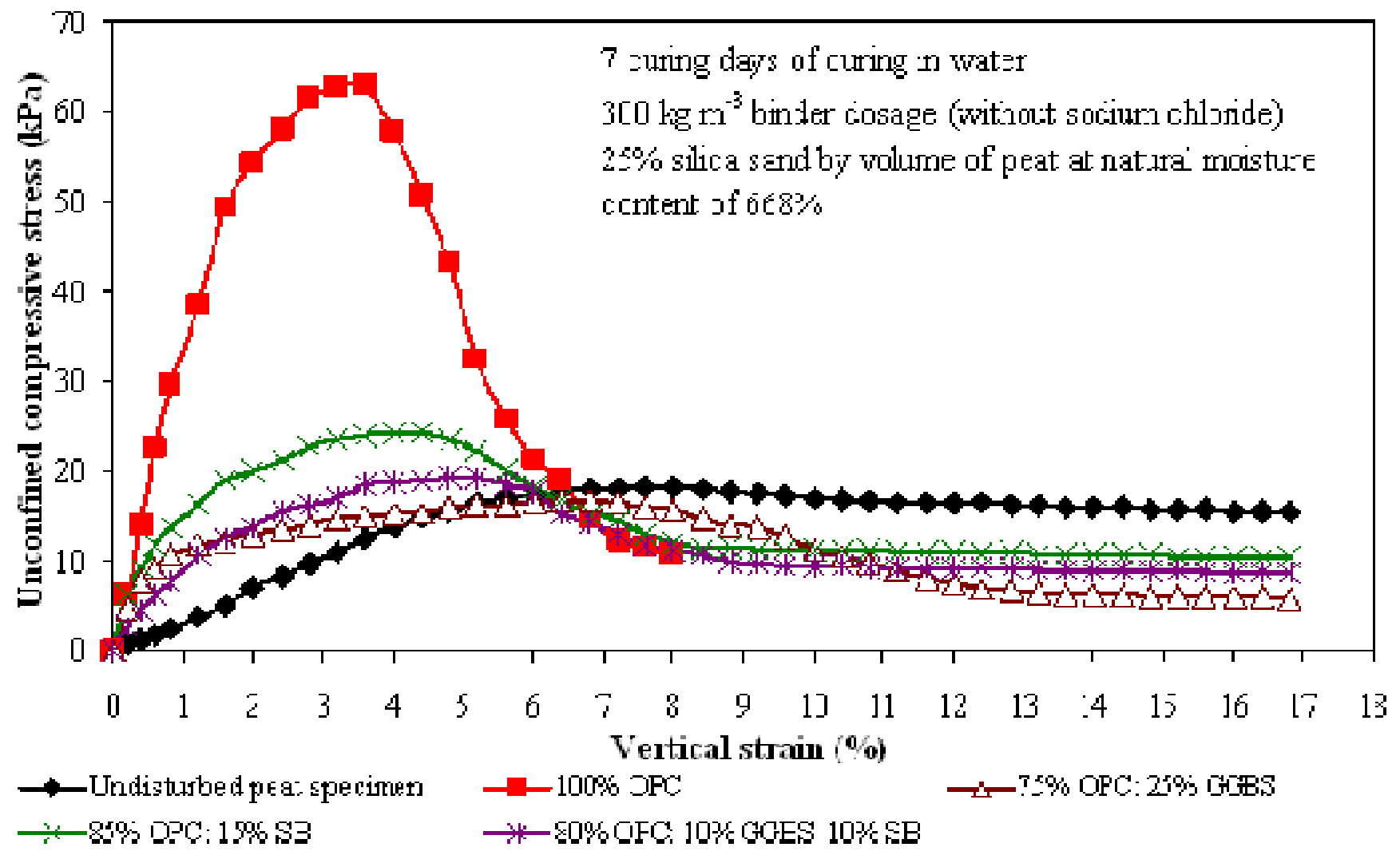

Figure 2. Unconfined compressive stress-vertical strain relationship of stabilized peat specimens at binder dosage of $300 \mathrm{~kg} \mathrm{~m}^{-3}$ and $25 \%$ silica sand by volume of wet peat without sodium chloride in comparison to that of undisturbed peat specimen.

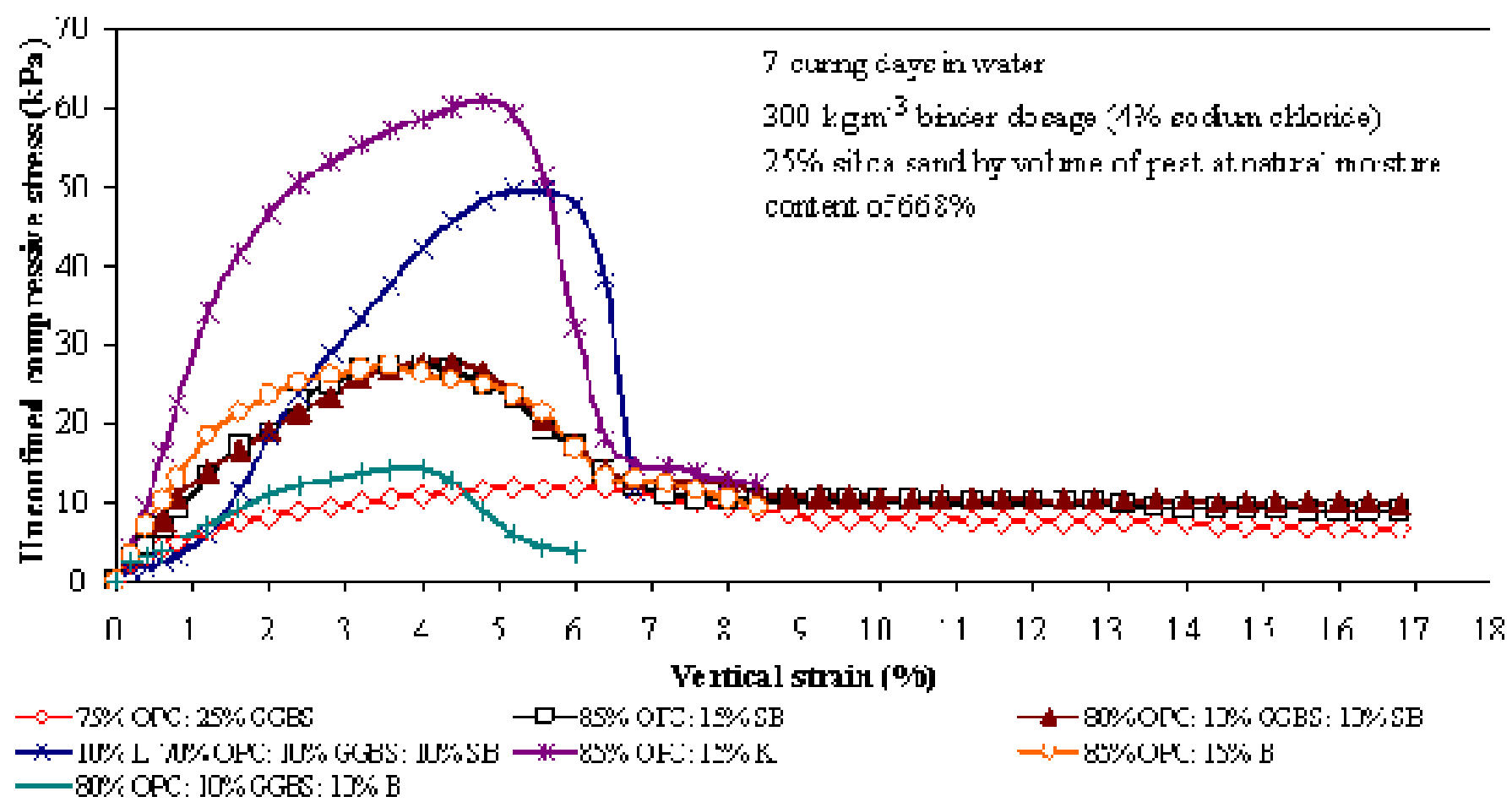

Figure 3. Relationship between unconfined compressive stress and vertical strain of stabilized peat specimens at binder dosage of 300 $\mathrm{kg} \mathrm{m}^{-3}, 25 \%$ silica sand by volume of wet peat, and $4 \%$ sodium chloride by weight of binder. 


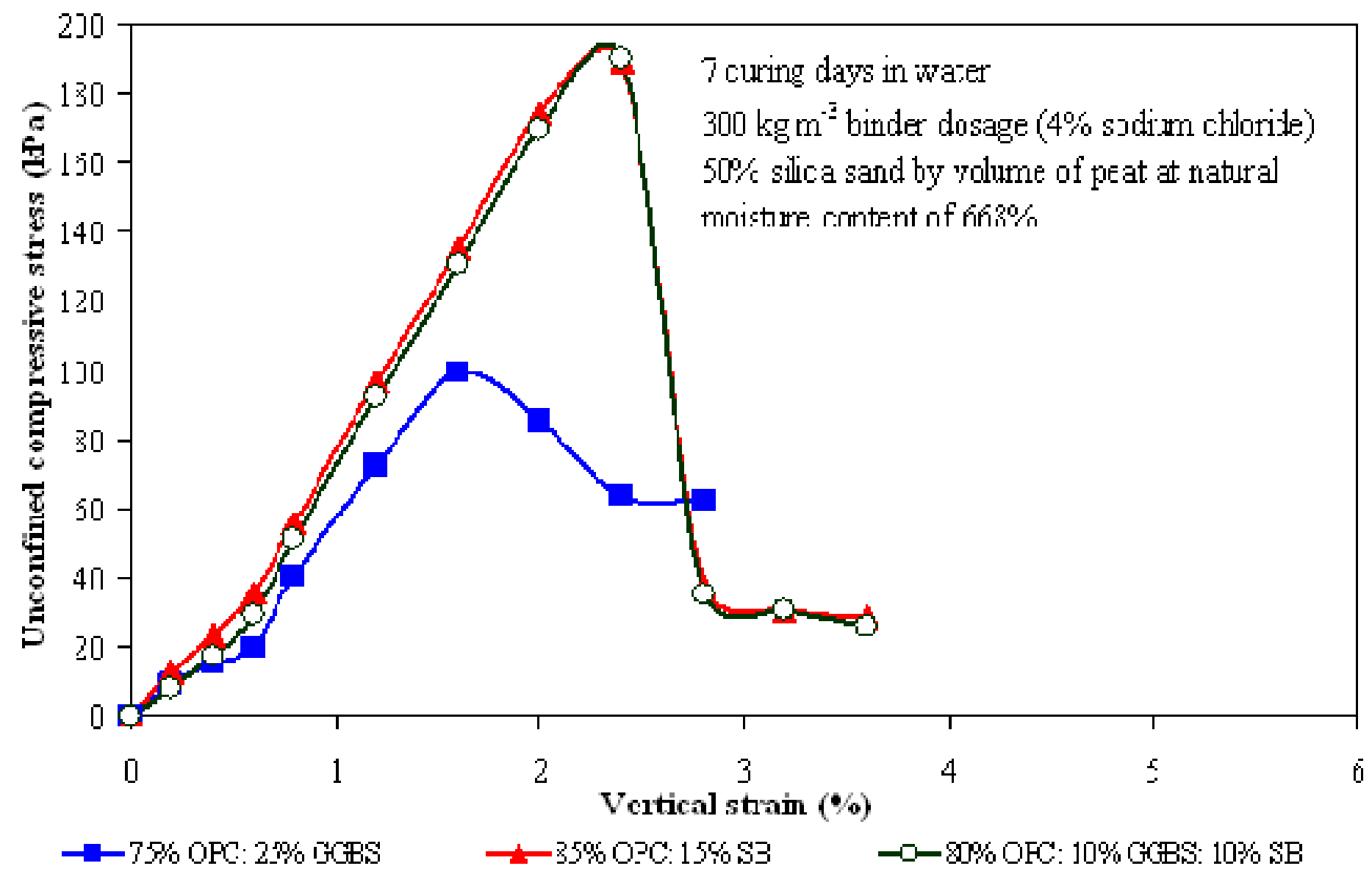

Figure 4. Relationship between unconfined compressive stress and vertical strain of stabilized peat specimens at binder dosage of $300 \mathrm{~kg} m$ $3,50 \%$ silica sand by volume of wet peat, and $4 \%$ sodium chloride by weight of binder.

that the presence of lime in the binder composition of 10\% L: $70 \%$ OPC: $10 \%$ GGBS: $10 \%$ SB with sodium chloride actually promoted the cement hydration and secondary pozzolanic reaction process. While addition of lime and cement into the wet peat basically produced more calcium hydroxide to react with slag and sodium bentonite in the stabilized soil admixture, inclusion of small amount of sodium chloride accelerated the rate of cement hydrolysis in saturated peat, thereby, speeding up the setting time and increasing the early strength gain of the stabilized soil.

The findings revealed that beside siliceous sand acting as filler, reactivity of sodium chloride as a cement acelerator in saturated peat was rather pozzolan specific. Therefore, at the binder dosage and $25 \%$ silica sand by volume of wet peat, not all pozzolans could react with cement having sodium chloride as an accelerator to produce stabilized peat with high early strength. As such, further research on the chemical reactivity of type of pozzolan with cement added with sodium chloride should be carried out in order to understand response of a typical pozzolan to the cement and sodium chloride in saturated peat.

\section{Impact of silica sand addition on the modulus of elasticity, vertical strain, and unconfined compressive strength of stabilized peat specimens with sodium chloride}

It was evident from Figure 4 that apart from sodium chloride as a cement accelerator and pozzolans as the contributing ingredients towards stronger stabilized peat, the high strength of the stabilized soil was also attributed to the addition of silica sand. It appeared that the more well graded silica sand added to the soil admixture, the more solid particles were present and the more cementation bonds were formed at the contact points between the solid particles, thus, interlocking the organic coarse and soil particles in peat to form stabilized peat structure characterized by high modulus of elasticity and unconfined compressive strength with small vertical strain at failure.

According to Ismail et al. (2002), the spherical particle of sand allows the sand to be exposed to more contact points within the surrounding grains, and this contributed to cemented matrix of many welded point to point contacts among the sand particles. Furthermore, the 
better graded grain distribution of the sand, the smaller the voids and the greater the number and the larger the interparticle contact surfaces, the stronger the effect of cementation (Kezdi, 1979).

\section{Conclusion}

Based on the study of unconfined compressive strength characteristics of stabilized peat, the following conclusions are drawn.

(i) At a dosage of $300 \mathrm{~kg} \mathrm{~m}^{-3}$ binder and $25 \%$ silica sand by weight of wet peat, specimen with a binder composition of $100 \%$ OPC gave the highest unconfined compressive strength of $63 \mathrm{kPa}$ in comparison to those of the rest of binder compositions tested without sodium chloride after 7 curing days in water. This is because the amount of cement was adequate to provide enough tricalcium silicate in saturated peat to neutralize the black humic acid, thus, promoting cement hydration and increasing the early strength gain of the stabilized soil specimen.

(ii) With addition of $4 \%$ sodium chloride by weight of binder at the same dosage of binder, silica sand and curing duration in water, the reactivity of wet peat to a binder composition is rather pozzolan specific. This is evident when a specimen with a binder composition of $85 \%$ OPC: $15 \% \mathrm{~K}$ yielded a significant unconfined compressive strength of $61 \mathrm{kPa}$ in the presence of sodium chloride in comparison to those of the rest of specimens with sodium chloride.

(iii) At the same dosage of binder and curing duration in water but with addition of $50 \%$ silica sand by mass of wet peat, all the specimens yielded high unconfined compressive strength. The high early strength gain of the specimens was largely contributed by the well graded solid particles in silica sand that enabled cementation bonds to be formed at contact points between the solid particles, thus, binding the organic and soil particles in saturated peat to form a stabilized peat structure.

\section{ACKNOWLEDGEMENT}

Funding of the research came from Postgraduate Research Fund PS016-2007B under University of Malaya Research University Grant. Acknowledgement is not complete without thanking Babak Kamali and Sadek Deboucha for giving constructive comments on the research article before it was sent for consideration to be published in Scientific Research and Essays.

\section{REFERENCES}

Axelsson K, Johansson SE, Andersson R (2002). Stabilization of organic soils by cement and puzzolanic reactions: Feasibility study. Linkoping (Sweden): 3rd Report of Swedish Deep Stabilization Research Centre. URL: www.swedgeo.se/sd/pdf/SD-R3E.pdf

Chen H, Wang Q (2006). The behaviour of soft soil stabilization using cement. Bull. Eng. Geol. Environ., 65: 445-448.

Hartlen J, Wolski W (1996). Embankments on organic soils. 1st edn. Elsevier Science B.V., Amsterdam, Holland. ISBN: 0-444-88273-1, p. 6.

Head KH (1994). Manual of Soil Laboratory Testing. Vol. 2: Permeability, Shear Strength and Compressibility Tests. 2nd edn., Pentech Press Limited, London, UK., ISBN: 0-7273 1319-3, pp: 582.

Ismail MA, Joer HA, Randolph MF, Meritt A (2002). Cementation of porous materials using calcite. Geotechnique, 52: 313-324.

Janz M, Johansson SE (2002). The function of different binding agents in deep stabilization. Linkoping (Sweden): 9th Report of Swedish Deep Stabilization Research Centre. URL: www.swedgeo.se/Sd/pdf/SD-R9E.pdf.

Karlsson R, Hansbo S (1981). Soil classification and identification, 1st edn. Stockholm: Swedish Council for Building Research.

Kezdi A (1979). Stabilized Earth Roads. 1st edn., Akademiai Kiado, Budapest, Hungary. ISBN: 0-444-99786-5, p. 110.

Landva AO, Pheeney PE (1980). Peat fabric and structure. Geotechnique, 17: 416-435.

Terzaghi K, Peck RB, Mesri G (1996). Soil Mechanics in Engineering Practice. 3rd edn. John Wiley and Sons, New York, USA. ISBN: 9780-471-08658-1, p. 127.

URL: www.ejge.com/2008/Ppr0862/Ppr0862.pdf.

Wong LS (2010). Stabilization of chemical binders and silica sand. Ph.D dissertation, University of Malaya, Kuala Lumpur, Malaysia.

Wong LS, Hashim R, Ali F (2008). Compression rates of untreated and stabilized peat soils. Elect. J. Geotech. Eng., 13: 1-13.

Wong LS, Hashim R, Ali F (2008). Influence of curing under stress on the engineering properties of stabilized peat soil. Proceedings of the International Conference on Construction and Building Technology, June 16-20, Grand Seasons Hotel, Kuala Lumpur, Malaysia, pp. 159179.

Xing $H$, Yang $X, X u$ C, Ye G (2009). Strength characteristics and mechanisms of salt-rich soil-cement. Eng. Geol., 103: 33-38. 